Supplement of Atmos. Chem. Phys., 18, 1863-1877, 2018

https://doi.org/10.5194/acp-18-1863-2018-supplement

(C) Author(s) 2018. This work is distributed under

the Creative Commons Attribution 3.0 License.

(c) (1)

Supplement of

\section{The effects of EI Niño-Southern Oscillation on the winter haze pollution of China}

Shuyun Zhao et al.

Correspondence to: Hua Zhang (huazhang@cma.cn)

The copyright of individual parts of the supplement might differ from the CC BY 3.0 License.

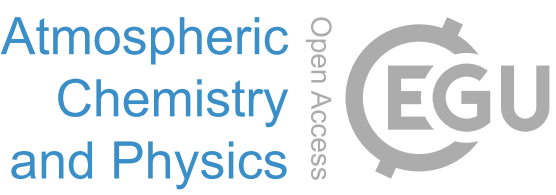

Atmospheric and Physics 


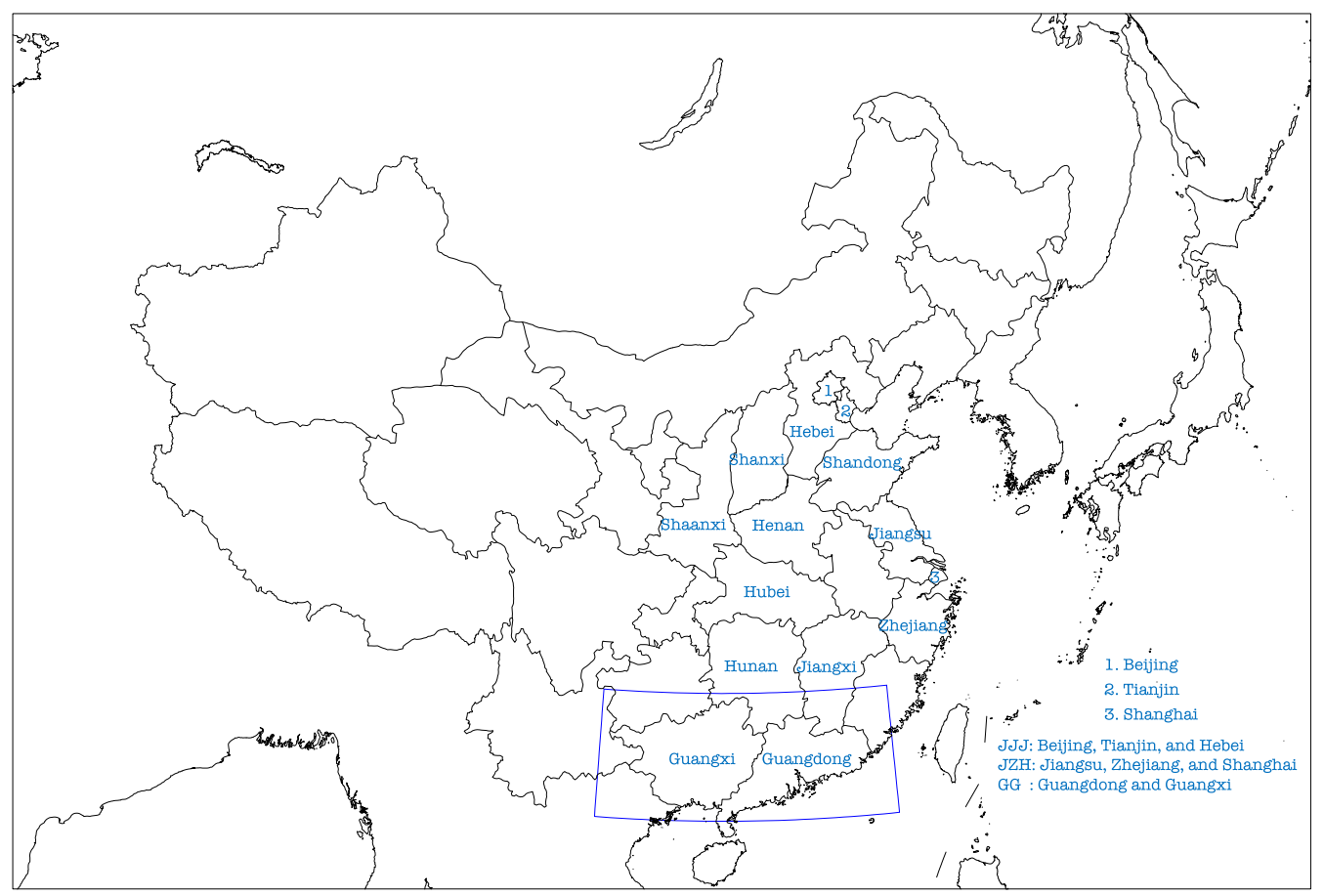

4 Figure S1. Names and short terms of the provinces and regions that are mentioned in section 3.1, with the box showing the scope 5 for calculating regional average aerosol CONCsur in Figure 10. 

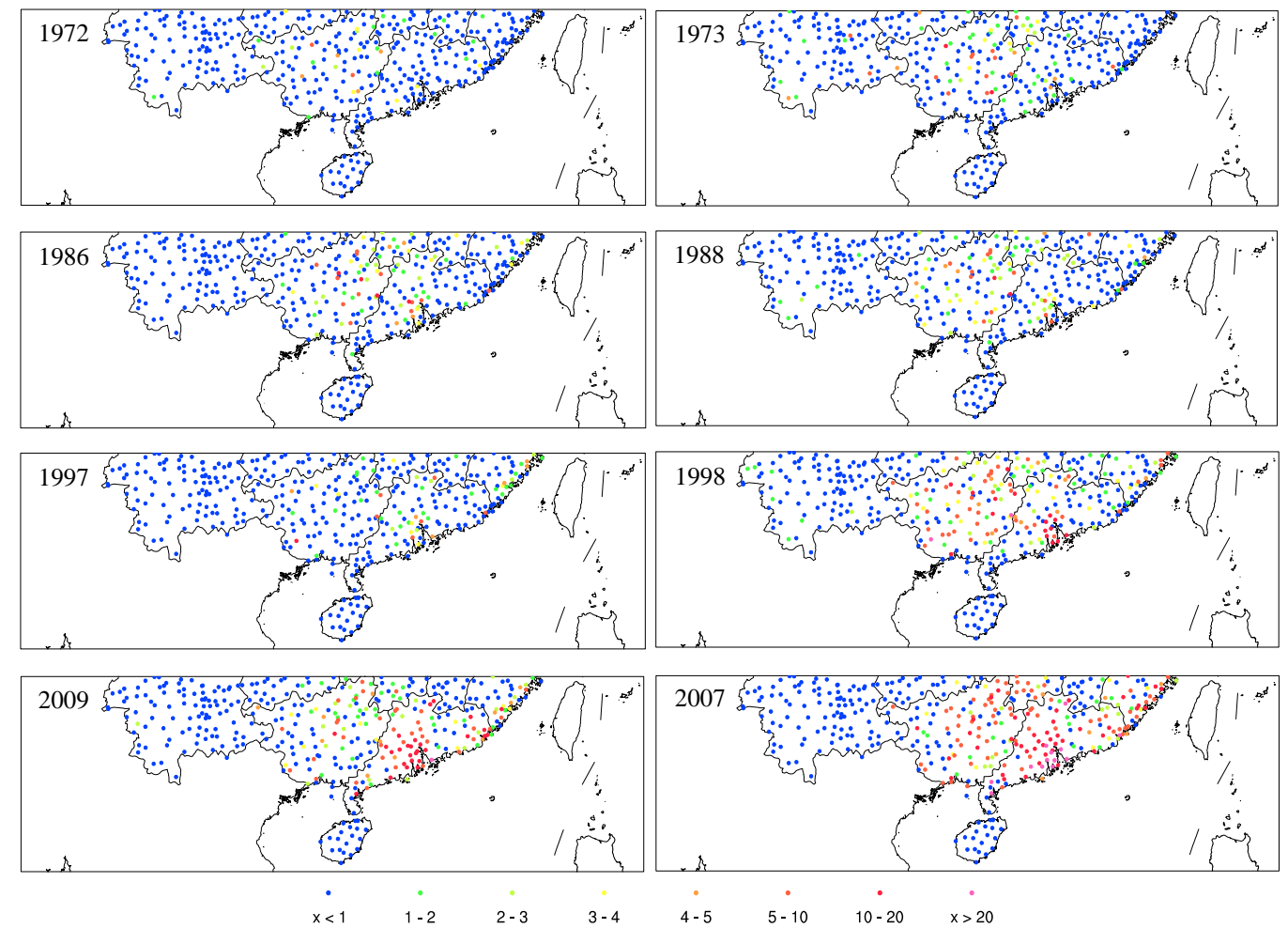

Figure S2. Comparisons between the average haze days (units: days) of 4 selected pairs of El Niño winters (left) and La Niña 3 winters (right) over southern China, with the interval between each pair not longer than 2 years. 


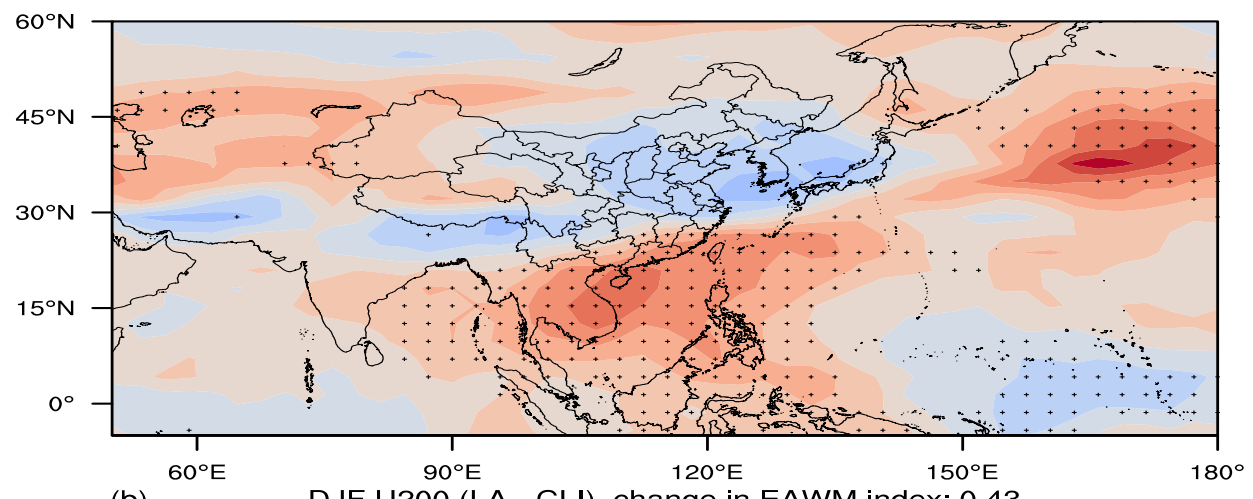

(b)

DJF U200 (LA - CLI), change in EAWM index: 0.43

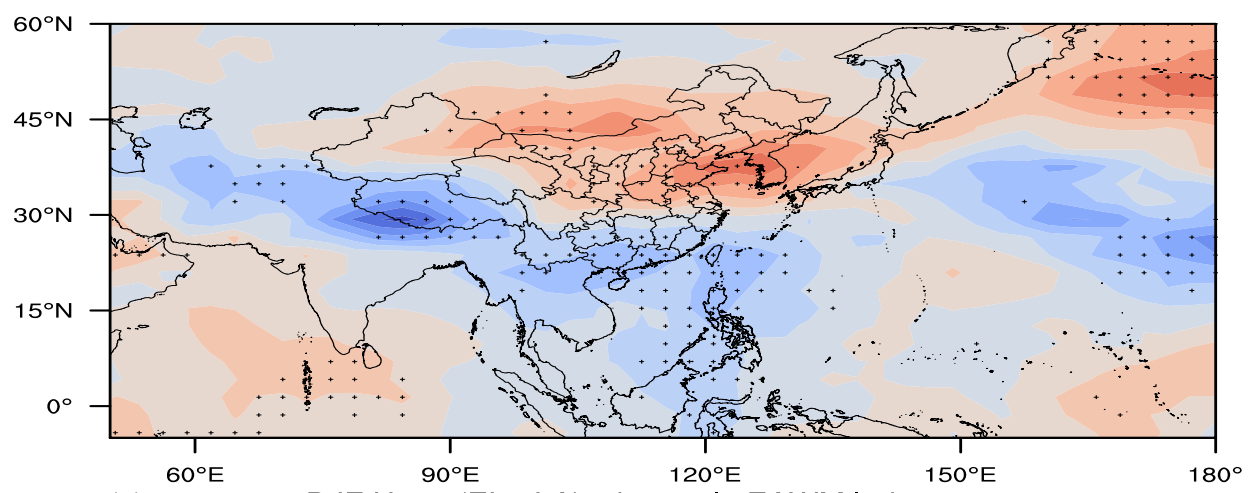

(c)

DJF U200 (EL - LA), change in EAWM index: -1.19

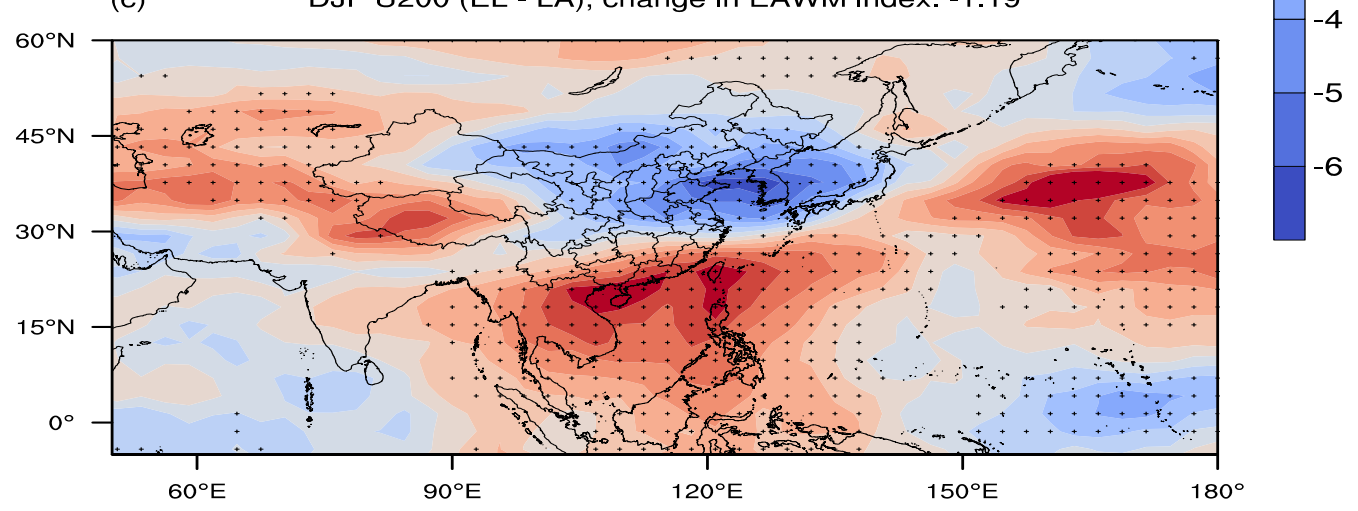

Figure S3. Medians of the simulated differences in winter-average zonal wind at $200 \mathrm{hPa}\left(\mathrm{U200}\right.$, units: $\left.\mathrm{m} \mathrm{s}^{-1}\right)$ between (a) EL and 3 CLI, (b) LA and CLI, and (c) EL and LA, with black "+" indicating that the differences in $\mathrm{U} 200$ between more than 70\% pairs of 4 ensemble members have the same sign with the median differences. The changes in East Asian Winter Monsoon (EAWM) index

( $\mathrm{Li}$ and Yang, 2010), which is calculated based on U200, are also given in titles. 
(a)

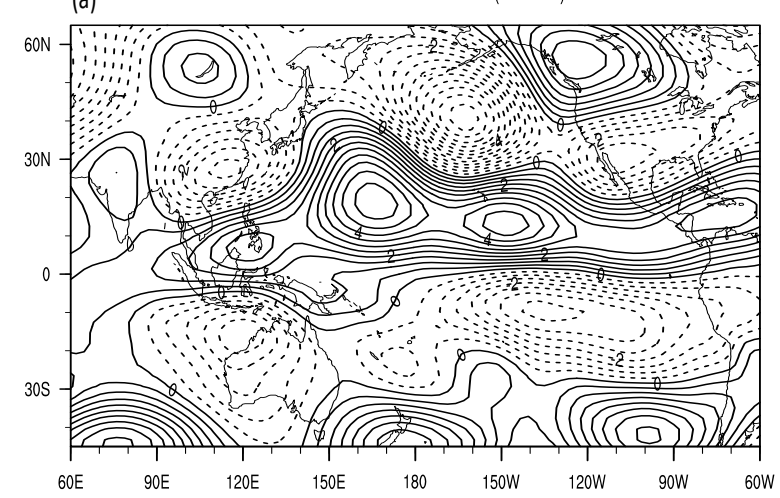

(b) 500 hpo streamfunction onomolies

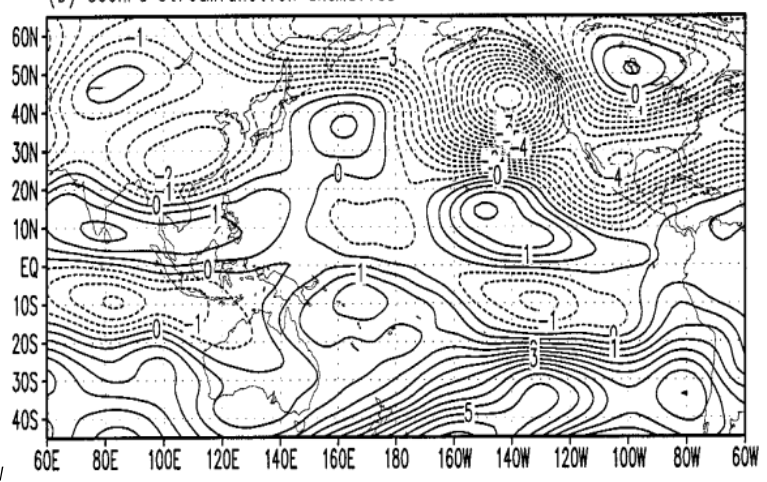

Figure S4. (a) Simulated differences in winter-average streamfunction at $500 \mathrm{hPa}$ between EL and LA, and (b) composite 3-month mean streamfunction anomalies at $500 \mathrm{hPa}$ around the peaks (in boreal winter) of six warmest ENSO events between 1958-1998, which is cited from Wang et al. (2000). Both (a) and (b) have a contour interval of 0.5 , and a unit of $10^{6} \mathrm{~m}^{2} \mathrm{~s}^{-1}$.

(a)

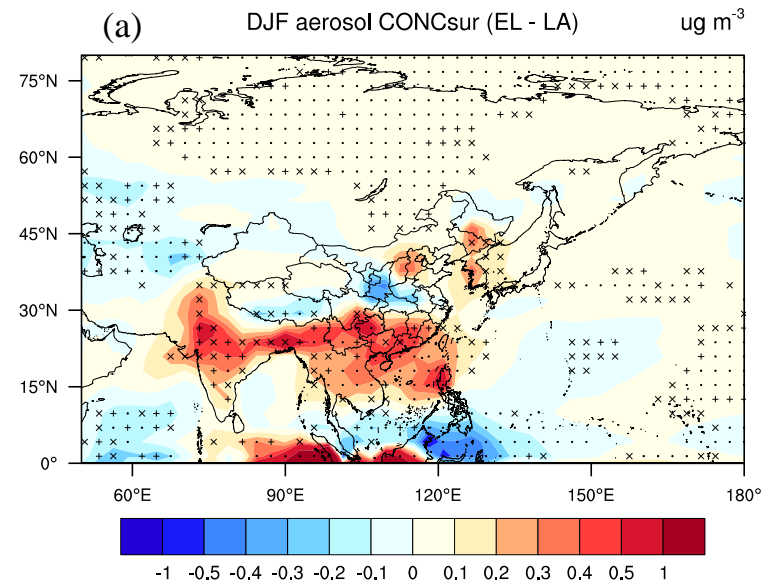

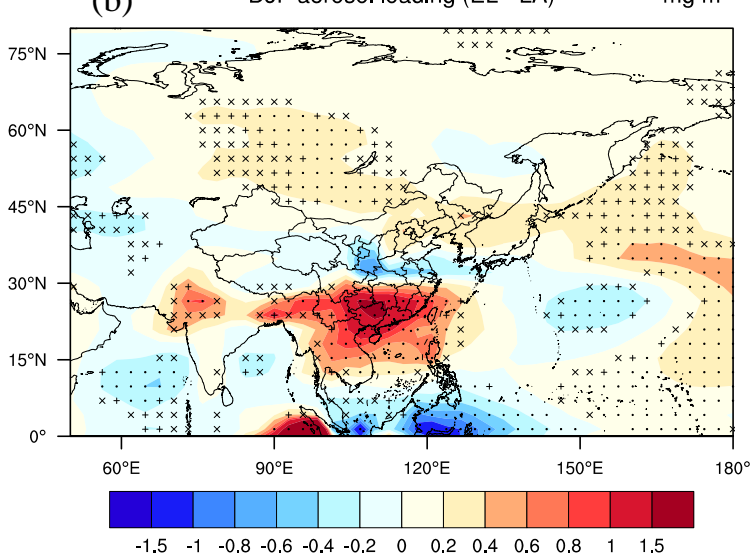

Figure S5. Means of the simulated differences in winter-average (a) aerosol surface concentrations (units: ug $\mathbf{~ m}^{-3}$ ) and aerosol loadings (units: $\mathrm{mg} \mathrm{m}^{-2}$ ) between EL and LA, with “ $\times$ ”, “+”, and "." indicating results significant at the levels of $0.2,0.1$, and 0.05 , 


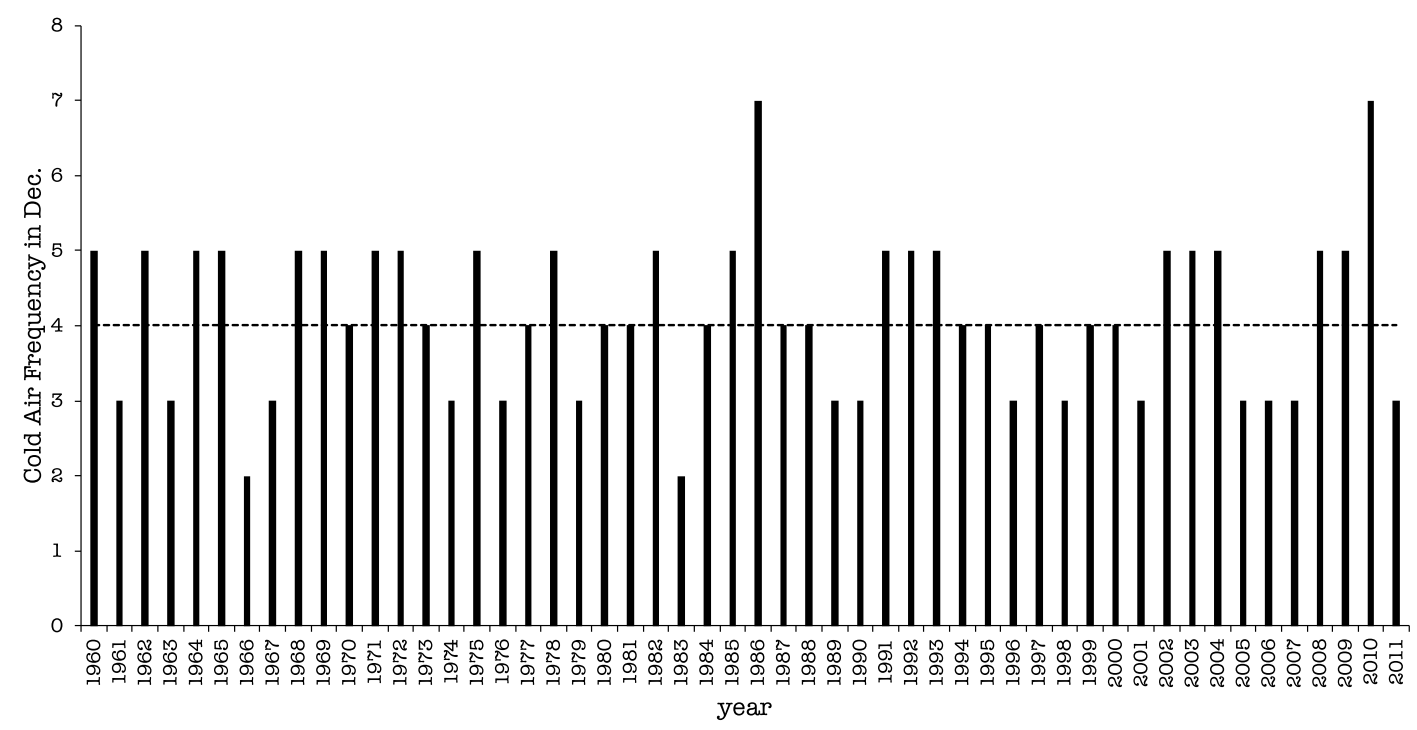
year

2 Figure S6. Recorded frequency of cold air in China in December between 1960-2011 by the National Climate Center of China. 3 

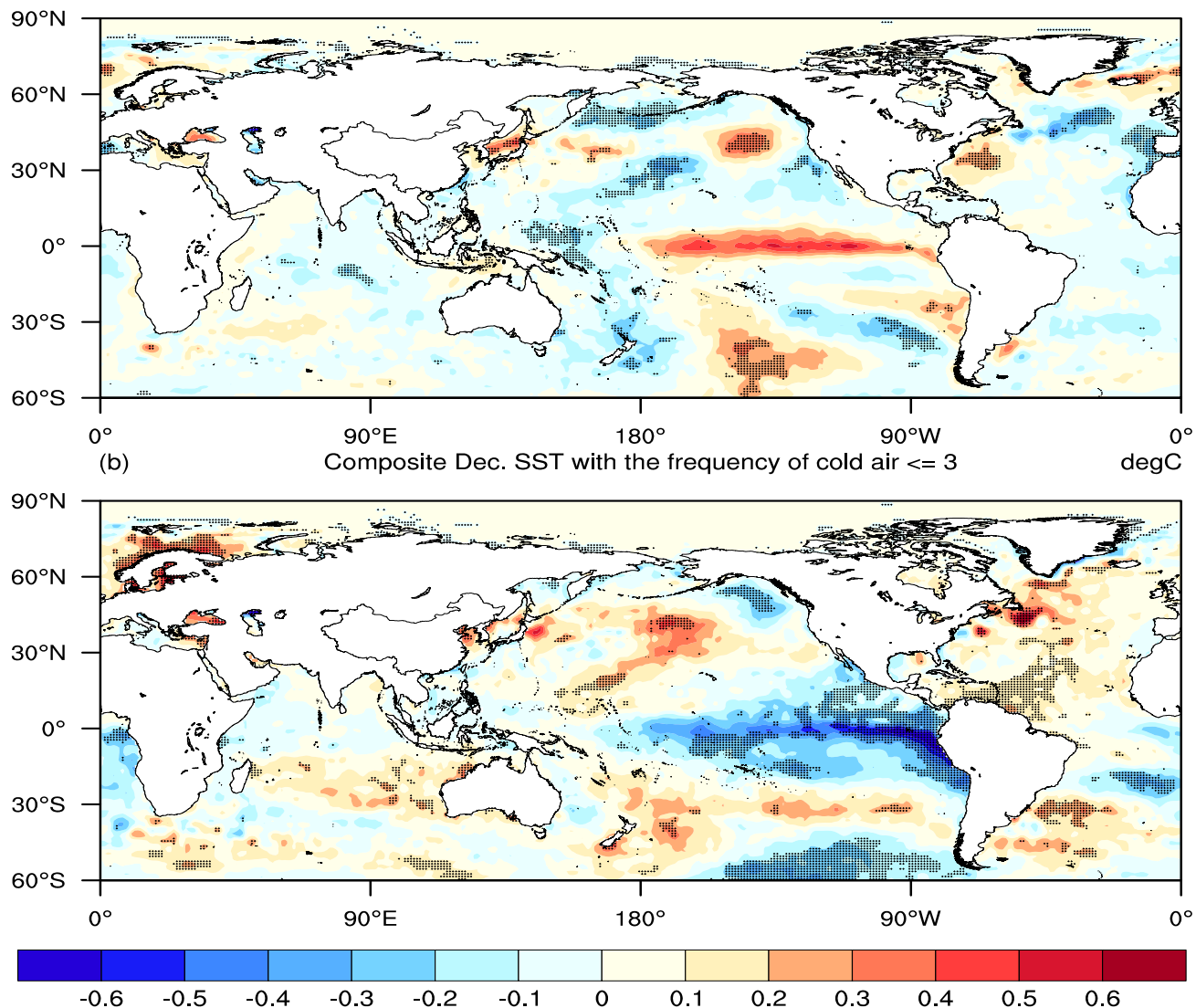

2 Figure S7. Composite of the anomalous sea surface temperature (SST, units: ${ }^{\circ} \mathrm{C}$ ) in December, with the frequency of cold air in 3 China in December (a) $\geq 5$ times and (b) $\leq 3$ times. Linear trend of the SST has been removed, and black dots indicate that results are significant at the level of $\mathbf{0 . 0 5}$. 